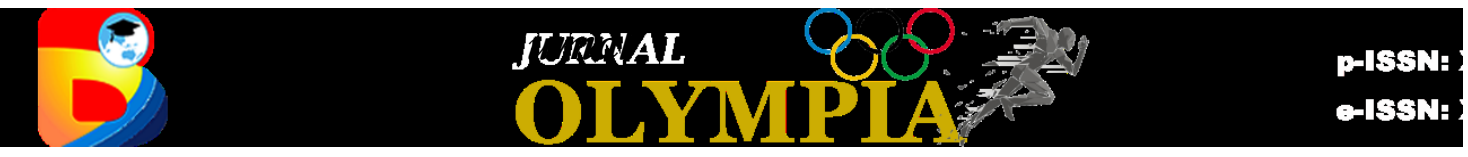

http://journal.binadarma.ac.id/index.php/olympia

\title{
Model Latihan Smash Bulutangkis Untuk Pemula Usia 8-10 Tahun
}

\section{Fandi Ahmad ${ }^{1}$}

Universitas Muhammadiyah Cirebon, Indonesia ${ }^{1}$

\begin{tabular}{l} 
Info Artikel \\
\hline Sejarah Artikel: \\
Diterima Februari 2020 \\
Disetujui Maret 2020 \\
Dipublikasikan \\
Mei 2020
\end{tabular}

Keywords: Exercise Model, Smash,

Badminton

\begin{abstract}
Abstrak
Penelitian ini bertujuan untuk; 1) menghasilkan produk berupa model latihan smash bulutangkis untuk pemula usia 8-10 dan 2) memperoleh data empiris tentang keefektifan hasil produk model latihan smash bulutangkis terhadap keterampilan smash atlit pemula usia 8-10 tahun. Penelitian ini menggunakan metode penelitian Research and Development $(R \& D)$. Subyek uji coba dalam penelitian ini adalah atlit pemula. Uji efektifitas peneliti eksperimenkan kepada 65 subjek selama 16 kali pertemuan. Tahap ini menghasilkan bahwa produk pengembangan efektif keterampilan smash bulutangkis. Menguji keefektifan model data yag didapatkan dari kelompok eksperimen rata-rata 19,57 dan kelompok kontrol 16,66 dengan uji signifikansi perbedaan dengan SPSS 16 didapat hasil t-hitung $=-11.320<1.669, \mathrm{df}=64$ dan sig. 2-tailed $=0,000<$ 0,05 yang berarti terdapat perbedaan yang signifikan keterampilan smash sebelum dan sesudah diberi model latihan smash bulutangkis. Dalam penelitian ini dapat diambil kesimpulan jadi produk berupa model latihan smash bulutangkis untuk usia 8-10, setelah diuji dalam uji efektifitas (1) Model telah terbukti meningkatkan keterampilan smash bulutangkis secara efektif dan efisien pada atlet pemula. (2) Penelitian telah berhasil dilaksanakan dan telah dihasilkan sebuah produk model latihan smash bulutangkis untuk pemula. (3) Dengan model latihan smash bulutangkis yang telah peneliti kembangkan, yang mana subyeknya atlet pemula usia 8-10 tahun dapat melakukan teknik smash bulutangkis dengan tepat dan benar.
\end{abstract}

\begin{abstract}
This research aims to; 1) to produce products in the form of badminton smash exercise model for beginner age 8-10 and 2) to obtain empirical data about the effectiveness of the product of the badminton smash exercise model for beginner age 8-10 years old. This research uses Research and Development $(R \& D)$. The subjects of trials in this study were novice athletes. The effectiveness test of the researcher was experimented on 65 subjects during 16
\end{abstract}


sessions. This stage produces that product of effective development of badminton smash skills. Testing the effectiveness of the data model obtained from the experimental group averaged 19.57 and the control group 16.66 with the significance test difference with SPSS 16 obtained $t$-count $=-11.320<1.669, d f=64$ and sig. $2-$ tailed $=0,000<0.05$ which means there is a significant difference of smash skills before and after being given a model of badminton smash exercise. In this research, it can be concluded that the product is a badminton smash exercise model for beginner age 8-10 years old, after being tested in effectiveness test (1) The model has been proven to improve the skill of badminton effectively and efficiently at beginner athlete. (2) Research has been successfully implemented and has produced a product model of badminton smash exercise for beginners. (3) With the model of badminton smash exercise that researchers have developed, the subjects of the beginner athlete aged 8-10 years can perform the technique of smash badminton properly and correctly.

\section{PENDAHULUAN}

Latihan dapat didefinisikan sebagai peran aktivitas fisik yang sistematis yang bertujuan untuk meningkatkan kapasitas fungsional fisik dan daya tahan latihan. Menurut James Tangkudung (2006:8) latihan merupakan proses yang berulang dan meningkat guna meningkatkan potensi dalam rangka mencapai prestasi yang maksimum. Kualitas latihan yag baik tidak lepas dari rangkaian aktivitas latihan yang sistematis artinya tidak bisa sembarang untuk melakukannya seperti pendapat Harsono (2015:50) bahwa latihan atau training adalah proses yang sistematis dari berlatih atau bekerja, yang dilakukan secara berulang-ulang dengan kian hari kian menambah beban latihan atau pekerjaannya. Berulang-ulang maksudnya agar gerakan-gerakan yang awalnya sulit dilakukan menjadi semakin mudah dan akhirnya menjadi otomatisasi (bergerak secara otomatis) pada pelaksanaannya sehingga semakin menghemat energy (efektif). Hal ini senada dengan pendapat David Joyce dan Daniel Lewindon (2014:71) bahwa The aim of training is to provide a stimulus that is effective in improving performance. Kian hari berarti setiap kali secara periodik segera setelah tiba saatnya untuk ditambah bebannya jadi bukan harus setiap hari.

Bulutangkis merupakan olahraga permainan yang menggunakan shuttlecock, raket dan lapangan, dimainkan oleh dua orang dan/atau dua pasang laki-laki dan perempuan. Menurut Tony Grice (2008:ix) Badminton is one of the most popular sports in the world. It appeals to all age groups and various skill 
levels, and men and women may play it indoors or outdoors for recreation as well as competition. Pendapat lain mengenai definisi Bulutangkis dikemukakan oleh Herman Subarjah dan Satriya (2013:9) bahwa permainan bulutangkis merupakan olahraga yang menggunakan raket sebagai alat pemukul shuttlecock sebagai obyek yang dipukul dan tujuan dari permainan ini adalah memperoleh angka dan kemenangan dengan cara menyeberangkan dan menjatuhkan shuttlecock di bidang permainan lawan dan berusaha agar lawan tidak dapat memukul shuttlecock atau menjatuhkannya di daerah permainan sendiri. Untuk bermain bulutangkis membutuhkan teknik-teknik dasar yang harus diketahui dan dikuasai diantaranya yaitu sikap berdiri (Stance), teknik memegang raket (Grip), teknik langkah kaki (Footwork), dan teknik memukul bola (Strokes). Strokes yang baik harus dilatih secara terus menerus dengan menggunakan model latihan yang efektif dan efisien serta memiliki inovasi yang terbarukan, kombinasi Strokes pada permainan Bulutangkis sangat diperlukan seperti yang dikemukakan oleh Janusz Jaworski dan Michal Zak (2006:8) bahwa The effectiveness of the games of Badminton depends on many combinations of the factors which determine the effectiveness of coaching in badminton. Teknik memukul bola atau stroke merupakan inti dari permainan bulutangkis karena setelah posisi stance, grip dan footwork untuk mengejar shuttlecock seorang pemain tetap harus mengembalikan pukulan lawan dengan cara memukul seperti pendapat Daniel Young
Wen Tan, Huong Yong Ting dan Simon Boung Yew Lau (2017:132) yaitu The stroke is a motion of striking the shuttlecock from the ready position, moving on to the movements to strike the shuttle and finally, to return to the ready position.

Strokes atau teknik memukul bola menurut Herman Subarjah dan Satriya (2013:27) dikategorikan menjadi tiga jenis yaitu pukulan dengan ayunan raket dari bawah ke atas (underarm strokes), pukulan meyamping (sidearm strokes) dan pukulan dari atas kepala (overhead strokes). Pukulan underarm diantaranya servis, servis panjang atau tinggi, servis pendek, netting. Pukulan sidearm diantaranya drive. Pukulan overhead diantaranya lob, smash, dan dropshot. Dalam permainan bulutangkis teknik-teknik yang sering digunakan menurut Bipasa Seth (2016:20-22) yaitu The three most popular strokes are the smash, the clear and the drop.

Pukulan smash merupakan pukulan yang kencang dan menukik tajam ke area pertahanan lawan, seperti yang dikemukakan Zao Zhang et.al (2016:9-10) yaitu In the stroke, the shuttle is hit toward the opponent's court with high speed and at a steep downward angle. Pendapat tersebut bisa diartikan pemain memukul bola secepat mungkin untuk mendapatkan angka atau poin sehingga kemampuan smash yang mumpuni dan berkualitas sangat diperlukan untuk mencetak angka. Hal ini sesuai dengan pendapat Helal El Gizawy dan Abdel Rahman (2014:49) yang menyatakan bahwa smash in a badminton game is an important shot used as 
an offensive starting point. Rangkaian gerakan untuk menghasilkan pukulan smash yang akurat yaitu posisi tubuh, rotasi pinggang, perkenaan shuttlecock, ayunan tangan dan gerakan lanjutan (followthrough). Seluruh rangkaian itu harus dikuasai dengan baik, namun permasalahan yang sering terjadi pada seorang pemain pemula biasanya bervariatif mulai dari model latihan yang membosankan, kurangnya variasi latihan hingga program latihan yang kurang disusun secara sistematis. Pemula sendiri menurut Kamus Besar Bahasa Indonesia yaitu orang yang memulai atau mula-mula melakukan sesuatu. Dengan kata lain adalah atlet yang baru mulai belajar dan berlatih pukulan smash pada cabang olahraga bulutangkis. Atlet pemula memiliki rentang usia 8-10 tahun.

Prinsip-prinsip pembinaan/pelatihan untuk atlet pemula harus memahami keadaan dan kondisi psikologis atlet tersebut. Untuk itu peran latihan sangat menentukan prestasi yang akan diraih atlet tersebut. Latihan merupakan perencanaan dalam mencapai sesuatu yang diinginkan. Dalam latihan, membutuhkan penyusunan atau perencanaan program latihan hal ini berperan untuk mengarahkan latihan selama jangka panjang (waktu tertentu). Tujuannya adalah memaksimalkan adaptasi fisiologi, yang pada akhirnya dapat meningkatkan prestasi atau penampilan seorang atlet, Johansyah Lubis (2013:11).

Menurut Arista Kiswantoro (2016:83) dalam memberikan latihan bagi atlet pemula harus memiliki beberapa prinsip-prinsip dasar seperti: a) Sikap mental percaya diri, b) Sikap
Disiplin, c) Kemauan dan motivasi yang kuat, d) Kontrol diri e) Sikap optimis, f) Konsep diri dan Berpikir positif, g) Tanggung jawab, dan h) Sikap sportifitas. Selain itu melakukan penilaian terhadap kemampuan dan kemajuan harus mencerminkan kompetensi yang dimiliki sehingga memperoleh gambaran (profiles) secara utuh (Bangkit Seandi Taroreh, 2012:122-131). Untuk itu dalam melatih atlet pemula harus memperhatikan beberapa hal diatas. Dari hasil penjabaran di atas diketahui bahwa perlu dibentuk model latihan smash bulutangkis bagi pemula dengan memperhatikan karekteristik di atas.

\section{METODE PENELITIAN}

Penelitian pengembangan model latihan smash bulutangkis menggunakan metode penelitian dan pengembangan (Research and Development) dari Borg dan Gall (1983 : 775) yang terdiri dari sepuluh langkah dalam penelitian, antara lain: (1) Research and information collecting (2) Planning (3) Development of the preliminary from of product (4) Preliminary field testing (5) Main product revision (6) Main field test. (7) Operational product revision (8) Operational field testing (9) Final product (10) Dissemination and implementation.

Penelitian ini dilaksanakan di ekstrakulikuler Sekolah Dasar Negeri Baru 08 Pasar Rebo Jakarta Timur tahun 2018. Pemilihan pada kegiatan ekstrakulikuler dikarenakan kegiatan ini merupakan pengembangan minat dan bakat diluar aktivitas pembelajaran di kelas. Hal ini juga 
diungkapkan Bangkit Seandi Taroreh (2017:41-47) bahwa di luar negeri sekolahsekolah sudah mengembangan berbagai kegiatan aktifitas fisik. Subjek merupakan atlet berusia 8-10 tahun, pada tahap penelitian peneli menggunakan 15 subjek untuk uji kelompok kecil, 65 subjek uji kelompok besar dan 65 subjek untuk uji efektifitas. Teknik analisis data yang digunakan dalam penelitian ini berupa teknik analisis data kualitatif dan kuantitatif, teknik analisis data kualitatif adalah rangkuman data yang didapat dari hasil pengamatan dan penilaian ahli agar lebih mudah dipahami, sedangkan teknik analisis data kuantitatif digunakan untuk menganalisis data yang dihasilkan dari tes yang dilakukan pretest dan posttest melalui uji-t.

\section{HASIL DAN PEMBAHASAN}

Hasil dari analisis kebutuhan, uji ahli, kelompok kecil, dan kelompok besar di peroleh 21 model latihan smash. Dari 21 model latihan tersebut diperoleh data pretes melalui instrumen yang diberikan sebesar 1108 dan data post test mengalami peningkatan menjadi sebesar 1272 .

\section{PERBANDINGAN PRETEST} DAN POSTTEST

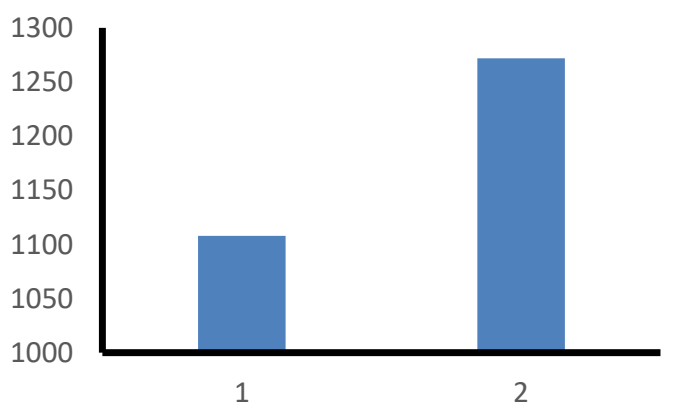

Gambar 1: Diagram Batang (Uji Coba Kelompok Besar)
Berdasarkan hasil dari analasis dengan menggunakan SPSS versi 20 membuktikan bahwa rata-rata yang diperoleh pada saat sebelum diberikan treatment model latihan smash bulutangkis untuk pemula sebesar 17,05 dan hasil rata-rata setelah diberikan treatment model latihan smash bulutangkis untuk pemula sebesar 19,57 . Selanjutnya hasil korelasi (correlation) antara 2 variabel tersebut sebesar 0,324 yang berarti memiliki hubungan yang cukup kuat dan positif. Setelah itu dapat dilihat nilai signifikan pada tabel paired samples correlations dari perolehan hasil yang didapat menunjukan tingkat signifikan sebesar 0,008 yang berarti memiliki nilai signifikan yang diperoleh dengan taraf signifikan 0,05. Selanjutnya dapat dilihat dari hasil df (degree of fredom/ derajat kebebasan) dimana $\mathrm{T}$ Paired menggunakan rumus $\mathrm{N}-1$ sehingga hasil yang diperoleh yaitu $65-1=64$. Kemudian nilai $\mathrm{t}$ hitung memperoleh hasil sebesar $-14,485$ yang berarti jika dibandingkan dengan $t$ tabel yang diperoleh lebih kecil yakni $-14,485<1.669$, namun dalam pembahasan ini dapat dilihat kembali pada nilai signifikan yang didapat yakni sebesar 0,000 yang berarti H0 di tolak. Untuk itu berdasarkan dari data yang diperoleh dapat dikatakan bahwa model latihan smash bulutangkis untuk pemula efektif dan dapat meningkatkan keterampilan smash untuk pemula.

Model latihan smash bulutangkis untuk pemula usia 8-10 tahun dikembangkan dalam 21 variasi dan sudah melalui uji validasi ahli. Guru atau pelatih pada saat latihan harus 
memperhatikan faktor taktik permainan, teknik, psikologis (mental bertanding) dan juga fisik (komponen biomotirik). Hal ini juga pernah diterapkan pada cabang olahraga lain bahwa untuk meningkatkan teknik keterampilan harus memperhatikan komponen biomotorik (M. Haris Satria dan Bangkit Seandi Taroreh, 2019:44-50).

Produk yang dikembangkan ini bertujuan untuk membentuk meningkatkan tercapainya tujuan latihan smash untuk pemula. Produk ini setelah dikaji terdapat beberapa kelemahan yang perlu pembenahan dan beberapa keunggulan produk ini antara lain:

1. Siswa lebih aktif dalam mengikuti proses belajar sambil bermain.

2. Siswa terlihat gembira dan antusias.

3. Model pembelajaran dilakukan dari yang mudah ke yang sulit.

4. Tingkat kompetisi yang tinggi sehingga membuat siswa lebih bersemangat.

5. Memerlukan saranan yang lebih banyak dari latihan yang bersifat konvensional tetapi mampu diterapkan sesuai dengan karakteristik pemula.

\section{SIMPULAN}

Berdasarkan data yang diperoleh, dari hasil penelitian yang terdiri dari validasi ahli, uji coba kelompok kecil dan uji coba kelompok besar serta pembahasan dari hasil penelitian, maka peneliti dapat menarik kesimpulan bahwa.

1. Model latihan smash bulutangkis untuk pemula dapat dikembangkan dan diterapkan dalam latihan pada anak usia 8-10 tahun.
2. Model latihan smash bulutangkis yang telah dikembangkan, diperoleh data efektifitas dan hasil model latihan smash bulutangkis untuk pemula usia 8-10 tahun.

\section{DAFTAR PUSTAKA}

Zhao Zhang et.al. (2016). The Influence of XFactor (Trunk Rotation) and Experience on the Quality of the Badminton Forehand Samsh, 53, 9-10.

Bipasa Seth. (2016). Determination Factors of Badminton Games Performance, 3(1), 20-22.

Herman Subarjah dan Satriya. (2013). Kepelatihan Permainan Bulutangkis, 9.

Daniel Young Wen Tan, Huong Yong Ting dan Simon Boung Yew Lau. (2017). OnCourt Holistic Badminton Training Analytics Framework, 35(8), 132.

Herman Subarjah dan Satriya. (2013). Kepelatihan Permainan Bulutangkis, 9.

Gavid Joyce dan Daniel Lewindon. (2014). High-Performance Training for Sports, 71.

Harsono. (2015). Kepelatihan Olahraga: Teori dan Metodologi, 50.

James Tangkudung. (2006). Kepelatihan Olahraga: Pembinaan Prestasi Olahraga, 8.

Janusz Jaworski dan Michal Zak. (2016). Identification of Determinations of Sports Skill Level in Badminton Players Using The Multiple Regression Model, 17(1), 21.

Bangkit Seandi Taroreh. (2012). Model Performance Assessment of Learning Outcomes Of Volley Ball in Elementary School. Journal of Physical Education and Sports, 1(2), 122-131.

Bangkit Seandi Taroreh. (2017). Development Model Approach Through Exercise Kinesthetic Game Circuit for Children Ages 4-6 Years. Journal of Indonesian 
Physical Education and Sport, 3(1), 4147.

El Gizawy, Helal dan Abdel Rahman Akl. Relationship Between Reaction Time And Deception Type During Smash In Badminton, Journal of Sports Research, Vol. 1 (3), Alexandria University, Egypt, 2014.

Kiswantoro, Arista. Pembinaan Mental Bagi Atlet Pemula untuk Membantu Pengendalian Agresifitas, Jurnal Konseling GUSJIGANG, Vol. 2 (1), Universitas Muria Kudus, 2016

Lubis, Johansyah. Panduan Praktis Penyusunan Program Latihan. Depok: Raja Grafindo Persada, 2013.

M. Haris Satria., Bangkit Seandi Taroreh. (2019). Hubungan Kelincahan, Kecepatan, Dan Keseimbangan Dengan Keterampilan Menggiring Bola Pemain Sepakbola Universitas Bina Darma. Riyadhoh: Jurnal Pendidikan Olahraga,2 (1), 44-50.

Tony Grice. Badminton Steps to Success, Second Edition. United States of America: 2008.

Walter R. Borg, and Meredith D. Gall. Educational Research: An Introduction, 4th Edition. New York: Longman Inc, 1983. 